sponsibility will not have any appreciable effect on the level of health and welfare services taken as a whole is, perhaps, over-optimistic. Furthermore, if the proposals are accepted, this would seem to be a good opportunity for working out some system of payment for board members instead of relying on their good will, sense of duty and any other motives.

So far the Green Paper is simply a basis for discussion and should be considered in the light of the recommendations of the Seebohm Committee regarding effective family service and of the Royal Commission on Local Government in England (due later this year). It is nevertheless a definite step forward and will be well received. Such dissatisfaction as there may be is likely to come from the medical officers of health who-according to Dr David I. Williams, Dean of King's Cross Hospital Medical School-will be affected most by the proposals. It seems that they stand to lose a large measure of the autonomy which they now enjoy, and may not be appeased by the Minister's "peace offering" of a senior position on an area board as principal adviser on all medical professional matters and director of the "planning and operation of services department".

\section{Astronomy is Fun}

THE Astronomy, Space and Radio Board of the Science Research Council must be worried that some of its more ambitious plans may go the same way as those of the Nuclear Physics Board-the $300 \mathrm{GeV}$ machine, for example. Perhaps this is why the Science Research Council has just published a report containing a lively review of the scientific interests of the Astronomy, Space and Radio Board which leaves no doubt about the excitement of the board's activities. The review, written by Professor P. A. Sheppard and Professor Fred Hoyle, makes up the larger part of the report and gives an insight into British astronomy and space research as it is in 1968 as well as an indication of the directions it may take in the near future. It was written as an introduction to the Astronomy, Space and Radio Board's statement of its policy and programme which, together with reports from the Science Research Council's two other boards, forms the basis of planning for what the council calls its Five-Year Forward Look.

The board-responsible for astronomy and space research in Britain and for radio work in this fieldis well aware that implementation of its plans depends on the financial resources available to the Science Research Council. Its members must be hoping that the fascination of the recent developments in astronomy and space research, brought out well in the scientific review, will be a convincing argument for their cause. It looks as though astronomers and space scientists, at least, have realized the importance of skilled public relations-something British nuclear physicists have not yet grasped. While few people know what the $300 \mathrm{GeV}$ accelerator is expected to do, the Astronomy, Space and Radio Board is trying hard to convey an impression of the vistas now opening in astronomy and space science, and the opportunities which will be missed if promising lines of research are not followed up. The report comes back to earth for the benefit of those still not convinced to point out the value to industry of postgraduates trained in space research, which involves advanced technology and close collaboration with industry.

The authors of the report are careful not to be too ambitious or even costly in their plans. They even give one example of an offer from NASA to fly an experiment for a group from Oxford and Reading Universities on one of the Apollo series being turned down for lack of money. The board gives several other examples of areas where it may not be able to do all that it hoped, and it is rightly worried about the scientific return from participation in ESRO.

Just as the nuclear physicists were concerned about the proportion of their budget which would have gone on the European $300 \mathrm{GeV}$ machine, the Astronomy, Space and Radio Board is not happy about the share of its financial cake swallowed by ESRO, currently running at around 50 per cent. The board sets its face against a further unbalancing of the expenditure by increasing the proportion going to space research or the proportion within the space research budget going to ESRO rather than to the national space programme. So far as ESRO is concerned, the object should be to provide facilities which are beyond the scope of individual European states. Now that the only large scale project to be seriously tackled by ESRO - the Large Astronomical Satellite-has been cancelled, much of the British scientific case for participation has gone, in any case. The report points out that attempts are now being made by Britain and other member states of ESRO to revive the TD-I and TD-2 programme. These two satellites were designed for investigation of the Sun towards the maximum of the solar cycle, and in the opinion of the board are sophisticated enough to go some way towards justifying ESRO's case. The plan seems to be to keep one of the satellites, either in the ESRO programme or as a separate project to be financed by the states still interested, at present numbering perhaps eight out of a possible ten.

If it turns out that the TD satellites are, after all, cancelled, ESRO's programme will be of the same quality as that of some of the European national programmes even if greater in quantity. The scientific return will be much reduced, and the case for British withdrawal will be even stronger, although there is no need for a decision just yet; the earliest date Britain can withdraw is the end of 1971 (notice must be given before 1970). The advantage of an earlier decision, however, is that it removes uncertainties about what launchers are going to be available to British scientists in the future; as far as the board is concerned, the alternatives to ESRO are increased collaboration with NASA and building on the Black Arrow launcher programme.

Just now, the board is concentrating on a successor to the UK 3 satellite (now Aeriel 3) launched from the United States in May last year. A decision on this has been hanging fire for more than a year, but the ESRO crisis has helped to settle matters and it seems likely that agreement has now been reached-at a Washington meeting last month-for two more satellites in cooperation with the Americans. In the past, cooperation with the Americans has proved not only smooth but fruitful and cheap. Because NASA provides satellite launchings free, research is actually cheaper by this means than if Britain used her own rockets. American reaction at the recent meeting 
seems to have been so warm that instead of choosing between alternative payloads for a single satellite, two have been adopted for the early 1970s. The second, provisionally called UK 5, breaks new ground. For the first time, American experiments will be included in a British payload and carried in a British-built spacecraft. The satellite will be concerned with cosmic X-rays, and experiments from the University of Leicester group, University College, London, and possibly Imperial College, are in view. In the new field of X-ray astronomy, British scientists have gained an enviable position through an experiment on the first Anglo-American satellite and also from stabilized Skylark rocket flights from Woomera. So far, American experimenters have had limited opportunities for this kind of work. The Astronomy, Space and Radio Board is very happy about the inclusion of the American experiments, which it hopes will help repay American hospitality. UK 5 will be a relatively sophisticated vehicle, and may take some years to complete. A design study by an industrial firm is at present being arranged. The other new satellite, UK 4, can go ahead faster, as it makes use of spare flight equipment prepared for last year's Aeriel 3, and will carry similar radio experiments.

\section{Radio Telescope in Space}

RADIO astronomers in Britain must this week bo envious of their Amcrican colleagues who, if all goes well, will soon have at their disposal a satellite designed purely with radio astronomy in mind, and equipped to pick up low frequency radio signals from space which are not able to penetrate the ionosphere. The striking feature of the new satellite, the Radio Astronomy Explorer-A (RAE-A), is its two V-shaped aerials; the open end of one $V$ pointing downward at the Earth, the other $\mathrm{V}$ directed outwards. When the two aerials are fully deployed, the $\mathrm{X}$-shaped configuration which the structure will then have will be $1,500 \mathrm{ft}$ from tip to tip, or as long as the Empire State building is tall.

The interest of RAE-A, launched on July 4, is that it will be able to extend radio astronomy measurements to parts of the radio spectrum inaccessible from the Earth. So far, attempts to carry out this kind of measurement from satellites have been relatively crude. Ariel 2, for instance, carried an experiment to detect cosmic radio noise between $750 \mathrm{kHz}$ and $3 \mathrm{MHz}$ picked up by a small dipole antenna, a type of antenna which has poor directional qualities. RAE-A is the next step after the early elementary experiments; when fully deployed its enormous $V$ antennae will have a beam width, in the plane of the aerial, of about $30^{\circ}$ when it is receiving signals at a frequency of $3 \mathrm{MHz}$, compared with a beamwidth of $120^{\circ}$ for a dipole.

The deployment of such large aerials in space is not without its difficulties, however, and previous attempts to extend much shorter aerials from spinning spacecraft have been known simply to wrap the aerials around the body of the vehicle. The Americans are therefore being cautious on this occasion. The plan is to stop the spin of RAE-A once it has been injected into its final orbit at an altitude of 3,730 miles by releasing weights on the ends of wires, eliminating any small remaining spin by lining up the spacecraft in the Earth's magnetic field. Once this is done, the aerial booms can be extended, at first only to a length of $450 \mathrm{ft}$. They will remain at this length, gathering data, for a fortnight, while their behaviour is monitored by four TV cameras, which also serve to determine the source of the radio signals picked up by the aerials. If all goes well, the booms will then be extended a further $300 \mathrm{ft}$ to their maximum length.

Linear acrials such as the acrials on RAE-A just now seem the most promising configurations for satellite radio astronomy, as the dish aerials used for groundbased work are too heavy to be carried into space, even if they are made of metallic foil. This is one of the reasons radio astronomers are watching with interest the deployment of the $750 \mathrm{ft}$ booms, which mark quite an advance in space technology. At launch, the booms are stored within RAE-A as spools of flat tape, of silver-plated beryllium-copper alloy, $5 \mathrm{~cm}$ wide and $0.005 \mathrm{~cm}$ thick. As a motor unreels the spool, the tape curls to form a rigid tube about $1.25 \mathrm{~cm}$ in diameter. One of the problems is expected to be distortion of the tubes by the heating effect of sunlight to avoid this the tape is perforated to allow sunlight to penetrate the tube and heat it more uniformly.

The two aerials are not the only booms making RAE-A look more like a spider than a spacecraft. It also has two $60 \mathrm{ft}$ booms forming a dipole acrial, and a $630 \mathrm{ft}$ boom which is to help damp out small oscillations of the satellite.

In its 3,730 mile orbit, well above the blanketing effect of the ionosphere and most of the Earth's halo of electrons, RAE-A should do a good job. Its receivers are sensitive to nine frequencies in the range $450 \mathrm{kHz}$ to $9 \cdot 2 \mathrm{MHz} ; 10 \mathrm{MHz}$ is roughly the frequency below which signals cannot penetrate the ionosphere. The aerial pointing toward space will be used to map the galaxy at low frequencies. Low frequency measurements of radiation which may come from cosmic ray particles should help in understanding the origin of the particles and how they are accelerated, as well as giving some information on the magnetic fields in space. The upper aerial will also collect low frequency measurements of the Sun, a means of studying the corona out to distances about a third of the way to the Earth. The V-shaped aerial pointing downwards to the Earth will, on the other hand, be able to investigate radio emission from near the Earth, and the $120 \mathrm{ft}$ long dipole is to follow the radio bursts from Jupiter. The configuration of the two $V$ aerials, one pointing toward space and the other Earthwards, should help in separating cosmic signals and signals coming from the Earth's environment, hitherto one of the problems of radio astronomy satellites.

\section{Report from Wales}

A NEW variety of spring oat which is resistant to three races of mildew was granted plant breeders rights in December 1967. Called Mostyn, it has bcen developed at the Welsh Plant Breeding Station, Aberystwyth, whose annual report for 1967 (price 10s.) includes a description of the new variety. Mostyn has been developed from a complex cross involving the wild oat (Avena sterilis) which contributed the resistance to the mildew fungus, and three other varieties, Powys, Pennant and Condor. Mostyn, which combines high grain yields with resistance to mildew, appeared 